\title{
The Competency Model of Cross-border Entrepreneurs: An Empirical Study Based on QCE Framework
}

\author{
Rongjian $\mathrm{Yu}^{1, \mathrm{a}}$, Bo Chen ${ }^{2, \mathrm{~b}}$ and Liyao Xiang ${ }^{3, \mathrm{c},{ }^{*}}$ \\ ${ }^{1}$ School of Business Administration, Zhejiang Gongshang University, Hangzhou, Zhejiang, China \\ 2 School of Business Administration, Zhejiang Gongshang University, Hangzhou, Zhejiang, China \\ ${ }^{3}$ School of Business Administration, Zhejiang University of Finance \& Economics, Hangzhou, \\ Zhejiang, China \\ ayurongjian@hotmail.com, bbolang_chenbo@163.com, ‘xiangliyao2@126.com \\ *Liyao Xiang
}

Keywords: Cross-border entrepreneurs, Entrepreneurial competency model, QCE model, Multiple case studies.

\begin{abstract}
In the increasingly turbulent and complex Internet context, cross-border entrepreneurship is becoming the new norm of the entrepreneurial process, but the entrepreneurial competency of cross-border entrepreneurs is still a theoretical "black box". Based on the QCE theoretical framework, a multi-case empirical study of 36 cross-border entrepreneurs is used to construct a cross boundary entrepreneurial competency QCE model, including three dimensions of "entrepreneurial conduct, entrepreneurial talent, entrepreneurial spirit", and 11 two level dimensions and 35 competencies. The cross-border entrepreneurs can make decisions based on the QCE model for entrepreneurial choice, as well as the enhancement of entrepreneurial conduct, talent and spirit. They have important application value for cross-border entrepreneurship education, effective identification of entrepreneurs, related entrepreneurial management and incubation policies.
\end{abstract}

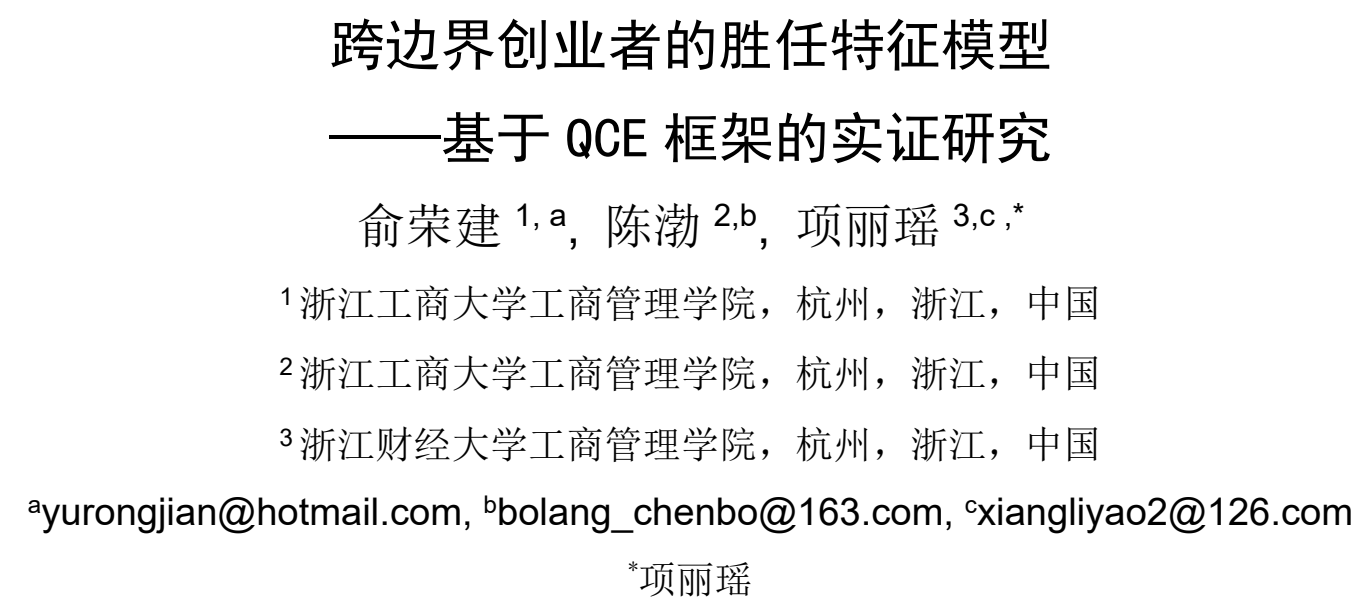

关键词：跨边界创业者；创业胜任特征模型；QCE 模型；多案例研究

摘 要:日趋动荡与复杂的互联网情境下，跨边界创业正成为创业过程的新常态，但是跨边界 创业者的创业胜任特征仍是个理论“黑箱”。基于 QCE 理论框架, 采用 36 个跨边界创业者的 多案例实证研究, 构建跨边界创业胜任特征 QCE 模型, 包含“创业品行、创业才能、创业精 神”三个维度, 以及 11 个二级维度以及 35 个胜任特征项目。跨边界创业者可以根据 QCE 模 型, 进行创业选择的决策, 以及创业品行、才能与精神的提升, 对跨边界创业教育、创业者 的有效识别以及相关创业管理与孵化政策, 具有重要应用价值。 


\section{1. 引言}

以互联网、电子商务等新兴技术与商业模式为代表的创业浪潮下，创业的多层次情境日 趋动荡与复杂化。在此情境下, 几乎所有的创业者都要经历连续的、跨界的多次创业活动, 以动态地适应创业环境的快速动荡。由此, 跨边界创业成为创业领域的新现象, 跨边界创业 者也将代表着一个新兴的主流创业群体。何种创业者, 能够成功实现跨边界创业? 创业者个 体层面, 影响跨边界创业绩效的关键因素是什么? 识别这些因素并且探索结构化、范式性的 理论框架, 构建跨边界创业的胜任特征模型, 是创业者研究领域的新命题。创业管理领域关 于创业者胜任特征的传统研究, 多关注一般性的创业胜任特征, 而对于新情境下跨边界创业 胜任特征的研究十分缺乏。本文基于 QCE 理论框架与跨边界创业案例研究, 探索并构建了跨 边界创业胜任特征模型。构建跨边界创业胜任特征模型, 对创业者研究具有理论新意; 对于 创业者的创业决策、创业投资的信号识别、以及创业教育与孵化政策制定, 都具有重要的现 实价值。

\section{2. 跨边界创业胜任特征仍是一个“黑箱”}

理论上, 跨边界创业者的胜任特征仍是个“黑箱”, 针对跨边界创业者的胜任特征模型十分 鲜见。少数涉及跨边界创业胜任特征的研究也存在诸多局限, 首先是理论上存在残缺, 只涉 及创业才能范畴, 而忽视了在创业活动中十分重要的创业品质、创业行为方式以及创业精神 等内容; 其次, 多是对胜任特征的简单罗列, 没有揭示跨边界创业胜任特征的内在结构。事 实上, 跨边界创业胜任特征项目之间存在结构性的关联机制, 创业胜任是一个结构性的集成, 而非离散（Thomas，2002）; 创业是一个复杂的系统工程, 某一项具体的专长或多项专长的 累积并不必然导致创业成功 ( J Gimeno et al.;1997) 。最后, 研究方法也存在一定的缺陷, 样 本选择通常是以成功的企业家作为分析对象，不符合胜任特征建模的规范方法。

跨边界创业胜任特征模型的构建，需要从两个方向上进行突破，一是理论上构建创业胜 任特征的结构维度, 二是通过实证研究探索每一个结构维度的具体内涵。本文整合两种典型 的胜任特征模型建构路径, 首先基于“理论推断一维度结构”路径, 运用经典的胜任力模型与 创业理论研究成果, 构建跨边界创业胜任特征的 QCE 框架; 其次基于“实证探索——胜任特 征”路径, 运用 16 个绩效优异的跨边界创业跨案例研究, 探索跨边界创业胜任特征; 第三, 整合两个路径的研究成果, 建构跨边界创业胜任特征模型; 最后, 阐述跨边界创业胜任特征 模型，在创业决策与选择，以及创业政策导向方面的应用与启示。

\section{3. 跨边界创业胜任特征的 QCE 框架}

跨边界创业胜任特征，指的是取得了显著创业绩效的跨边界创业者，所具备的特质集合。 具有两个属性: 一是与创业绩效显著关联。创业胜任特征指创业绩效显著与创业绩效平平的 跨边界创业者之间, 在个体特质上的差异部分, 正是这些差异部分导致绩效差异; 二是跨边 界创业者个体层面与创业相关的特质。创业胜任特征指跨边界创业者的个体特质, 而跨边界 创业者所处的家庭背景、社会关系以及所掌握的外部资源等, 不属于创业胜任特征范畴。跨 边界创业胜任特征模型, 是对创业绩效优秀的跨边界创业者样本, 所具备的胜任特征进行结 构化与系统化，所构建的模型。

借鉴创业与跨边界创业理论成果, 对相关文献 (冯华, 杜红,2005; 王瑞, 薛志红,2010; 陈 建安等, 2013; Carlsson B. et al. ,2013) 中涉及的理论要素进行了整合, 构建了跨边界创业胜 任特征的 QCE 框架, 包括创业品行、创业胜任力、创业精神等三个维度, 这三个维度内在地 决定跨边界创业者的创业绩效。作为创业之 “德”，创业品行构成模型的基石，是在中国文化 背景下跨边界创业成功的前提条件; 作为创业之“才”，创业胜任力构成模型的支柱，是创业 成功的必要条件; 作为创业之 “愿”, 创业精神是创业成功的源动力, 也是创业胜任特征中最 
为重要的维度, 强大的创业意愿和信念, 会催化、驱动创业品行与创业胜任力的提升, 因此 QCE 框架, 是“创业精神、创业品行与创业才能” 内在关联、相互驱动, 具有协同机理的系统 结构。对于跨边界创业者来说，必备的外部条件如资金来源、社会关系网络等，是创业成功 的必要保障, 属于“浮于海面”的显性特征, 而创业胜任特征的三个维度则处于“海面之下”, 从而难以直观地观测。

\section{1 创业品行维度（Quality \& Behavior）}

创业品行维度（Quality \& Behavior）指创业者在特定的创业情境下，所持有的基本伦理 品质和行为方式, 现实语境中常常用“好人/坏人”、“人品好/人品差”等词语来描述。本文认为, 跨边界创业者在中国特有的创业情境下从事创业活动, 首当其冲的是具有获得他人认同的基 本伦理品质和行为方式。这显然与跨边界创业者的创业绩效有显著关系, 特别是较长时期内, 品行对于跨边界创业者创业绩效的作用就会凸显出来。创业品行概念既有的研究较少, 多为 不同角度或者不同语境下的侧面描述。虽然对其建立具有严格边界、清晰内涵的概念维度, 目前具有相当的难度, 但是, 运用多案例研究, 来探索“优秀的跨边界创业者, 具有何种伦理 品质和行为方式? ”, 对创业品行进行结构化构建, 仍具有相当的理论意义。

\section{2 创业才能维度 (Competencies)}

现实语境中, “品行”维度回答一个人是不是一个“好人”, 而要达成一定的创业绩效, 除 了做一个“好人”之外，还要做一个“能人”。创业才能维度，指跨边界创业者从事创业活动， 应该具备的技巧（Skills）、知识(Knowledge)与能力（Abilities）。创业技巧指的是会操作某 一具体创业事项, 如相当的表达力、人际关系技巧等。创业知识指的是所创业务所涉及的专 业知识和技术等, 如淘宝网店的创业, 就需要熟悉大量的供应链管理、品牌设计与网络营销 等专业知识。创业技巧与创业知识都应用于确定环境下针对反复重复、具有明显规律的问题。 而创业过程中更关键、往往直接决定创业绩效的问题, 是新问题、十分复杂的问题或者高度 不确定性的问题。解决这些问题, 不仅仅需要技巧和知识的积累, 更需要创造性地将既有的 技巧、知识、经验和商业信息整合起来, 寻找到具有高效率、独特性的新的解决办法, 这便 是“解决问题能力”。

\section{3 创业精神维度 (Enterprenuarship)}

优秀的创业绩效，不仅需要跨边界创业者是个“好人与能人”，更重要的是一个有强烈“创 业信念” 的人。创业精神维度, 指的是跨边界创业者对于创业的执着程度, 既往的胜任力模型 多用“自我驱动、成就欲望、职业抱负、工作投入、敬业精神”等概念来刻画。对于跨边界创 业者而言, 则体现为创业活动的激情与热爱、创业目标的信念和执着以及对待风险的态度等。

创业绩效

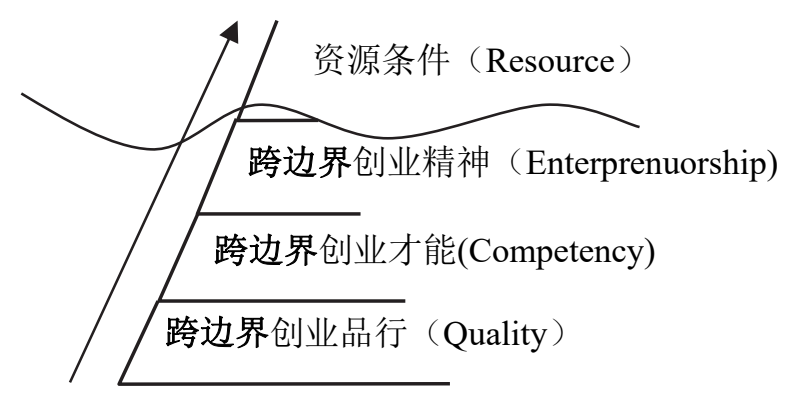

图 1 跨边界创业胜任特征的 QCE 框架 


\section{4. 跨边界创业胜任特征的多案例实证研究}

按照胜任特征建模的规范方法, 按照一定的创业绩效评价标准, 选择 16 个创业绩效显著 优秀的跨边界创业者, 进行半结构化的行为事件 (BEI) 访谈, 建立胜任特征库, 再基于 QCE 框架对胜任特征库进行结构化，构建跨边界创业胜任特征模型。

\section{1 跨边界创业者样本选择}

鉴于跨边界创业者的内涵特征，本文通过各种信息渠道，初步搜集 95 个跨边界创业者案 例。根据创业绩效理论, 结合跨边界创业者的特殊性, 建立创业绩效评价标准, 运用“盈利状 况排序、成长性排序、风险性排序”三个指标, 选择其中 36 个创业绩效显著优于其他的案例 作为研究对象。36 个跨边界创业者绩优案例的第一个特点, 全部分布在互联网、电子商务、 经销零售以及服务行业（生活服务或者生产性服务）等所谓“轻公司”行业。这不是偶然，而 是因为研究对象的外延限定, 跨边界创业者天然地适于从事这些非资本密集型行业的创业; 第二个特点, 男性占绝大多数, 36 位创业者中, 男女性别比例为 33:3, 这也是符合我国现时 社会的性别分工和女性的创业取向; 第三个特点, 36 个创业绩优案例的企业规模差异显著, 既有年营收近亿元的成型企业, 也有刚刚起步但是势头良好的 2-3 人小团队。这说明创业成 功, 并不能以规模论之, “小而美”的创业企业同样可以精彩。

\section{2 跨边界创业行为事件访谈}

对跨边界创业者样本进行“行为事件访谈”（Behavioral Event Interview，简称 BEI）。BEI 是一种开放式的行为回顾式探索技术, 是揭示胜任特征的主要工具。这种方法是目前在构建 素质模型过程中使用得最为普遍的一种。它通过对访谈对象的深入访谈, 收集访谈对象在任 职期间所做的成功和不成功的事件描述，挖掘出影响目标岗位绩效的非常细节的行为。之后 对收集到的具体事件和行为进行汇总、分析、编码, 然后在不同的被访谈群体 (绩效优秀群 体和绩效普通群体）之间进行对比, 就可以找出访谈对象的胜任特质。研究者采用如下三个 主要问题, 对选择的大学生创业者案例进行了访谈：(1)请您介绍一下您创业的基本历程、核 心业务和业绩状况; (2)您多次跨界创业经历中, 对目前的创业成功最关键的事件是什么？您 在其中起着什么作用? (3)如果用三个形容词来描述您个人在创业过程中的优势, 哪三个词最 准确? 为什么?

\section{3 研究结果}

对 36 个跨边界创业者创业案例行为事件访谈的现场记录, 采用文本分析方法, 对访谈结 果进行解构、编码、分类和结构化。首先按照语义, 对每一个案例的访谈记录文本, 提取信 息单元, 再对信息单元进行编码和分类, 形成了包括 94 个编码化信息单元的胜任特征库, 这 些胜任特征库都有明确的关键事件支撑, 语义相互独立; 其次, 对 94 个胜任特征, 进行结构 化分类和和整合, 形成内涵相对独立的 11 个二级维度; 最后, 分别将 11 个二级维度, 按照 内涵录属, 归结到创业品行、创业才能和创业精神三个维度中。从而完成大学生创业胜任特 征模型的构建。 
表 1 跨边界创业胜任特征模型

\begin{tabular}{|c|c|}
\hline \multirow{3}{*}{$\begin{array}{l}\text { 跨边界 } \\
\text { 创业 } \\
\text { 精神 }\end{array}$} & $\begin{array}{l}\text { 信念坚定: (1)愿景明确: 对创业有明确的蓝图; (2)坚定持久: 不会因为短期困难而 } \\
\text { 退却, 具有充分的耐心; (3)充分投入：发挥潜能、对创业全身心投入; }\end{array}$ \\
\hline & $\begin{array}{l}\text { 追求卓越: (1)战略认知: 能够区分战略性与事务性的工作内容; (2)卓越导向: 对于 } \\
\text { 关键性的任务工作力求完美, 对于非关键性的任务控制精力投入, 能够容忍残缺; } \\
\text { (3)关注细节: 对关键细节具有高度敏感性并亲力亲为; }\end{array}$ \\
\hline & $\begin{array}{l}\text { 风险倾向: (1)风险意识: 对创业风险具有充分的认知; (2)风险承担: 愿意承担创业 } \\
\text { 失败的后果与责任; (3)风险应对: 对可能的风险具有相应的应对策略; }\end{array}$ \\
\hline \multirow{3}{*}{$\begin{array}{c}\text { 跨边界 } \\
\text { 创业 } \\
\text { 才能 }\end{array}$} & $\begin{array}{l}\text { 基本技能: (1)沟通技能: 出众的口才; (2)人际关系技能: 善于处理与各种社会角色 } \\
\text { 的人际关系; (3)业务技能: 熟悉所创业务的做法; }\end{array}$ \\
\hline & $\begin{array}{l}\text { 创业知识: (1)商业知识: 战略分析与商业运作知识; (2)技术概念：熟悉所在行业的 } \\
\text { 技术发展动态与趋势; }\end{array}$ \\
\hline & $\begin{array}{l}\text { 创业能力: (1)商业洞察力: 在复杂的商业情境中能够敏锐发现新的商业机会和潜在 } \\
\text { 商业价值的能力。(2)解决问题能力: 在复杂、冲突与不确定的情境下, 运用掌握的 } \\
\text { 信息、技巧、知识和经验, 高效率地解决问题的能力; (3)创造力: 发现新的商业机 } \\
\text { 会、寻找新的方法等达成目标的能力; (4)学习能力: 能够快速高效地适应创业需要 } \\
\text { 进行学习和领悟; }\end{array}$ \\
\hline \multirow{5}{*}{$\begin{array}{c}\text { 跨边界 } \\
\text { 创业 } \\
\text { 品行 }\end{array}$} & 诚信品质： 1诚实守信：相比于商业利益，更加珍视商业信誉和行业口碑; \\
\hline & $\begin{array}{l}\text { 分享品质: (1)正确的利益观: 对于利人利已的事情全力以赴, 力求共赢; (2)乐于分 } \\
\text { 享: 能从与人分亭利益中获得快乐; }\end{array}$ \\
\hline & $\begin{array}{l}\text { 责任品质: (1)承担“加”责: 力求把事情做到位; (2)独立担当: 如果做不到位主动承 } \\
\text { 担责任; (3)承担“减”责：不做有背法律或商业原则与伦理的事; }\end{array}$ \\
\hline & $\begin{array}{l}\text { 客户导向行为: (1)客户价值观: 将“为客户创造价值”作为使命, 极度重视用户体验; } \\
\text { (2)长期导向: 相比于短期利益, 注重与客户的长期合作; }\end{array}$ \\
\hline & $\begin{array}{l}\text { 团队合作行为: (1)人际兼容: 能与各种特征的人共处; (2)才队角色: 勇于承担领导 } \\
\text { 者角色; (3)冲突处理：站在所创事业发展的立场处理团队冲突。 }\end{array}$ \\
\hline
\end{tabular}

基于创新的 QCE 框架, 通过多案例探索性研究, 构建的跨边界创业胜任特征模型, 具有 三个方面的价值：（1）系统揭示了跨边界创业胜任特征的“黑箱”。案例研究发现, 跨边界创 业胜任特征不仅仅包含创业才能维度, 还发现创业精神与创业品行在跨边界创业活动中尤其 重要, 验证了 QCE 框架的先验性理论假设; （2）探索了跨边界创业胜任特征模型各个维度 的具体特征项目。通过多案例研究和行为事件访谈, 发现创业绩效优秀的跨边界创业者在创 业中的典型特征, 这些特征具有示范意义; （3）方法论上，基于 QCE 框架、采用规范的胜 任特征建模方法所构建的跨边界创业胜任特征模型, 包括三个一级维度、 11 个二级维度、35 个具体特征项目, 结构化程度高、逻辑清晰, 比传统的胜任力冰山模型在涵盖性和逻辑性上 具有明显优势。

\section{5. 跨边界创业胜任特征 QCE 模型的启示}

跨边界创业胜任特征的 QCE 模型对于创业者和创业教育，都具有相应的启示意义。 对于潜在的跨边界创业者而言, 首先需要识别自身是否具备跨边界创业的先决条件, 即创业 精神。选择创业, 就是选择与风险、不确定性相伴。创业精神维度要求跨边界创业者必须具 备内生的风险偏好特质。如果不具备这一特质，即便具有很强烈的创业意愿，也往往是带有 盲目性的冲动。其次, 如果属于明确的风险偏好类型, 则在创业前期, 还要明确所创业务可 能存在的风险情境、储备必要的创业才能和品行。案例研究发现, 大多数创业失败的跨边界 创业者, 虽然认知上明确创业风险, 但是对于潜在的具体风险情境, 缺乏预案。再次, 在创 业前期要通过各种方式, 高效地补充创业所需的关键才能, 如专业知识、技术与相关商业信 息, 以提高成功的概率; （2）对于已经在跨边界创业路上的创业者而言，有进有退地坚持信 念、持续不断地学习和探索、检验和校正商业伦理观与行为方式, 不断地完善自我的品行、 
能力和创业愿景，在创业道路上首先达成自我的提升，继而实现商业上的成就;（3）对于创 业教育而言, 创业教育需要将教育的重点, 要从创业课程教育、传播创业知识, 转变为跨边 界创业者创业精神、创新和创造力、以及创业品行的立体开发。在创业教育对象遴选上，既 要进行“创业教育“，也要进行“不创业教育”，对部分不适合创业的跨边界创业者，给予专业 和中肯的建议。在创业教育的方式上, 要从课堂授课教育等“纸上谈兵”的方式, 拓展为多种 多样“干中学”的教育方式, 成立各种形式的跨边界创业者创业孵化载体, 在孵化载体中辅导 跨边界创业者从小而新的创业项目开始，修炼创业品行、提升创业才能、强化创业精神。

\section{致谢}

本文为浙江省哲学社会科学规划项目 (14NDJC138YB)、浙江省自然科学基金重点项目 (批准号 LZ15G030001) 、浙江省软科学研究计划项目（批准号 2016C25013; 2016C35G2140136）; 国家自然科学基金面上项目（批准号 71273238）; 中国博士后科学基 金面上项目（批准号 2017M621897）、浙江工商大学现代商贸研究中心项目（批准号 15SMGK21YB )的阶段性成果之一。

\section{References}

[1] Carlsson, B., Braunerhjelm, P., McKelvey, M., Olofsson, C., Persson, L., \& Ylinenpää, H. (2013). The evolving domain of entrepreneurship research. Small Business Economics, 2013 , 41 (4) :913-930.

[2] CHEN Jian-an, JIN Jing, FA He. Analysis of Research Frontier of Entrepreneurial Competencies and Future Prospects[J]. Foreign Economics \& Management, 2013 , 35 (9) :2-14.

[3] FENG Hua,DU Hong. Analysis of the relationship between entrepreneurial competency and entrepreneurial performance [J]. Technoeconomics \& Management Research, 2005 (6) :17-18.

[4] J Gimeno , TB Folta , AC Cooper , CY Woo .Survival of the Fittest? Entrepreneurial Human Capital and the Persistence of Underperforming Firms[J]. Administrative Science Quarterly, 1997, 42 (4) :750-783.

[5] THOMAS WYM, THERESAL. The competitiveness of small and medium enterprise: a conceptualization with focus on entrepreneurial competencies[J]. Journal of Business Venturing, 2002 (17):123-142.

[6] WANG Rui, XUE Hongzhi. Entrepreneurial Experience and New Venture' s Performance: A Literature Review[J]. Science of Science and Management of S.\&.T., 2010 (06) : 80-84. 